
\title{
R Reserach S Suare \\ Takotsubo Cardiomyopathy after Hypoglycemia in a Patient with Anorexia Nervosa
}

\section{Kota Kikuchi}

Dokkyo Medical University

Norio Yasui-Furukori ( $\nabla$ furukori@dokkyomed.ac.jp )

Dokkyo lka Daigaku https://orcid.org/0000-0002-4414-3770

Chie Hasegawa

Dokkyo Ika Daigaku

Aimi Watabiki

Dokkyo Ika Daigaku

Teruo Inoue

Dokkyo Ika Daigaku

Kazutaka Shimoda

Dokkyo Ika Daigaku

\section{Case report}

Keywords: Takotsubo cardiomyopathy, hypoglycemia, anorexia nervosa, eating disorders

Posted Date: March 23rd, 2021

DOl: https://doi.org/10.21203/rs.3.rs-345352/v1

License: (c) (1) This work is licensed under a Creative Commons Attribution 4.0 International License.

Read Full License 


\section{Abstract}

\section{Background}

Takotsubo cardiomyopathy, also known as "apical ballooning syndrome", is generally precipitated by endogenous or exogenous stress, and eating disorders have a variety of physical complications.

\section{Case presentation}

We present a case involving a 37-year-old Japanese female with eating disorders. She was admitted because of emaciation with shortness of breath and tiredness, and her weight was $30.0 \mathrm{~kg}$ (BMI 10.5 $\mathrm{kg} / \mathrm{m}^{2}$ ) at this admission. On the afternoon of the first hospital day, a simple measurement caused hypoglycemia of $20 \mathrm{mg} / \mathrm{dL}$, and she lost consciousness. On the night of the second hospital day, electrocardiogram showed negative T waves in II, III, aVf, and V1-6. Ultrasound echo showed hypokinesia at the apex of the heart and hypercontraction at the base of the heart. The left ventricular ejection fraction was $20 \%$. Rest and oxygen administration gradually improved her cardiac function; the left ventricular ejection fraction also improved to $50 \%$ based on echocardiography. Finally, her weight increased by $43 \mathrm{~kg}$ (BMI $15.2 \mathrm{~kg} / \mathrm{m}^{2}$ ) with psychiatric treatment, and she was discharged.

\section{Conclusions}

The present case shows the clinical features of Takotsubo cardiomyopathy induced by a hypoglycemic event in addition to underlying anorexia nervosa.

\section{Background}

Takotsubo cardiomyopathy, also known as "apical ballooning syndrome", is a cardiac disease characterized by transient left ventricular apical wall motion abnormality without epicardial coronary

artery disease. ${ }^{1}$ This cardiomyopathy is generally precipitated by endogenous or exogenous stress, and eating disorders have a variety of physical complications. We report a case of suspected Takotsubo cardiomyopathy after hypoglycemia accompanied by anorexia nervosa.

\section{Case Presentation}

We present a case involving a 37-year-old Japanese female with eating disorders. Eighteen years earlier, she described episodes of binging and purging and weight loss (42 kg, BMI 16.4) with amenorrhea. She was diagnosed with eating disorders, and she was admitted to the Department of Psychiatry 5 times because of abnormal weight loss. She was then admitted because of emaciation with shortness of breath and tiredness, and her weight was $30.0 \mathrm{~kg}\left(\mathrm{BMl} 10.5 \mathrm{~kg} / \mathrm{m}^{2}\right)$ at this 6th admission. Laboratory tests at admission revealed the following: aspartate aminotransferase $1731 \mathrm{IU} / \mathrm{L}$; alanine transaminase $1210 \mathrm{lU} / \mathrm{L}$; gamma-glutamyltransferase $277 \mathrm{U} / \mathrm{L}$; creatinine $0.43 \mathrm{mg} / \mathrm{dL}$; urea nitrogen $29 \mathrm{mg} / \mathrm{dL}$; phosphorus $3.1 \mathrm{mEq} / \mathrm{L}$; sodium $137 \mathrm{mEq} / \mathrm{L}$; potassium $4.5 \mathrm{mEq} / \mathrm{L}$; chlorine $99 \mathrm{mEq} / \mathrm{L}$; white blood cell 
count $2800 / \mu \mathrm{L}$; red bold cell count $40.7 * 109 / \mu \mathrm{L}$; hemoglobin $14.1 \mathrm{~g} / \mathrm{dL}$; platelets $9.3 * 104 / \mu \mathrm{L}$; and troponin I (sensitive assay) $0.006 \mathrm{ng} / \mathrm{mL}$. Her ECG showed a heart rate of $57 / \mathrm{min}$, P-R interval of 0.247 $\mathrm{sec}$, and corrected QT interval of $0.464 \mathrm{sec}$. On the afternoon of the first hospital day, a simple measurement caused hypoglycemia of $20 \mathrm{mg} / \mathrm{dL}$, and she lost consciousness. This loss of consciousness was improved by administration of $50 \%$ glucose solution, and the $50 \%$ glucose solution was coinjected into the maintenance infusion. On the night of the second hospital day, the electrocardiogram monitor revealed tachycardia, and a 12-lead electrocardiogram was performed. Sinus rhythm was observed, but negative T waves were observed in II, III, aVf, and V1-6 (Figure 1). Ultrasound echo showed hypokinesia at the apex of the heart and hypercontraction at the base of the heart, suggesting Takotsubo cardiomyopathy. The left ventricular ejection fraction was $20 \%$. Refeeding syndrome also appeared and became hypophosphatemia, and we provided phosphorus. Rest and oxygen administration gradually improved her cardiac function; the left ventricular ejection fraction also improved to $50 \%$ based on echocardiography. Her amount of food intake gradually increased, and we provided psychotherapy. On the 12th day, treatment for eating disorders was continued, as her general condition was improving. Finally, her weight increased by $43 \mathrm{~kg}\left(\mathrm{BMI} 15.2 \mathrm{~kg} / \mathrm{m}^{2}\right)$ with psychiatric treatment, and she was discharged.

\section{Discussion And Conclusions}

The present case shows the clinical features of Takotsubo cardiomyopathy induced by a hypoglycemic event in addition to underlying anorexia nervosa. There have been a few case reports of Takotsubo cardiomyopathy and eating disorders. ${ }^{2-11}$ In particular, reports of only 5 cases have suggested a relationship between Takotsubo cardiomyopathy and hypoglycemia in addition to eating disorders. ${ }^{3-5,9,10}$ The average age and range were 29.2 years and 16 and 49 years, and 4 of 5 patients were female. However, according to epidemiological studies, approximately $90 \%$ of Takotsubo syndrome patients are aged 50 years or more. ${ }^{12}$

This case meets Takotsubo cardiomyopathy diagnostic criteria I (Transient hypokinesis, akinesis, or dyskinesis of the left ventricular mid-segments with or without apical involvement; the regional wall motion abnormalities extend beyond a single epicardial vascular distribution; a stressful trigger is often, but not always present) and III (New electrocardiographic abnormalities (either ST-segment elevation and/or T-wave inversion) or modest elevation in cardiac troponin) but not criteria II (Absence of obstructive coronary disease or angiographic evidence of acute plaque rupture) and IV (Absence of: Pheochromocytoma and Myocarditis).${ }^{13}$ Coronary angiography did not rule out a significant lesion, and biopsy did not rule out myocarditis. Therefore, the diagnosis was suspected Takotsubo cardiomyopathy, which was not definitive. Nevertheless, we believe that this case was Takotsubo cardiomyopathy caused by stress due to hypoglycemia.

Although it is difficult to predict Takotsubo cardiomyopathy in advance, frequent measurement of blood glucose levels is necessary to prevent extreme hypoglycemia. Additionally, Takotsubo cardiomyopathy 
commonly occurs in postmenopausal females. ${ }^{12}$ One of the risk factors is the decrease in estrogen associated with menopause. In fact, the current patient had irregular menstruation since high school due to anorexia nervosa, and her blood estrogen level was lower $(11.8 \mathrm{ng} / \mathrm{ml})$ than that of women of the same age.

\section{Declarations}

\section{Authors' contributions}

$\mathrm{KK}, \mathrm{CH}$ and $\mathrm{AW}$ were involved in the management of the patient. This case report was written by NYF. TI and KS revised the manuscript. All authors read and approved the final manuscript.

\section{Funding}

Not applicable.

\section{Availability of data and materials}

The data used for this case report is available from the corresponding authors on reasonable request.

\section{Ethics approval and consent to participate}

There was no need for approve for the publication of this case report in Ethics committee in Dokkyo Medical University Hospital.

\section{Consent for publication}

Written informed consent has been obtained from the patient for the publication of this case report.

\section{Competing interests}

The authors declare that they have no competing interests. This edit was made to conform to the format of the journal guidelines.

\section{References}

1. Amin HZ, Amin LZ, Pradipta A. Takotsubo Cardiomyopathy: A Brief Review. J Med Life. 2020;13(1):3-7. 
2. Rotondi F, Manganelli F, Lanzillo T, Candelmo F, Lorenzo ED, Marino L, Stanco G. Tako-tsubo cardiomyopathy complicated by recurrent torsade de pointes in a patient with anorexia nervosa. Intern Med. 2010;49(12):1133-7.

3. Volman MN, Ten Kate RW, Tukkie R. Tako Tsubo cardiomyopathy, presenting with cardiogenic shock in a 24-year-old patient with anorexia nervosa. Neth J Med. 2011;69(3):129-31.

4. Vadalá S, Pellegrini D, Verdaguer MF, Schrappe M, Alvarez J, Bruetman JE. Stress (Takotsubo) cardiomyopathy in a patient with anorexia nervosa. Medicina. 2014;74(3):222-4.

5. Shimizu K, Ogura H, Wasa M, Hirose T, Shimazu T, Nagasaka H, Hirano K. Refractory hypoglycemia and subsequent cardiogenic shock in starvation and refeeding: report of three cases. Nutrition. 2014;30(9):1090-2.

6. Madias JE. Cardiac arrest-triggered takotsubo syndrome vs. takotsubo syndrome complicated by cardiac arrest. Int J Cardiol. 2016;225:142-3.

7. Kawano H, Kinoshita M, Kondo A, Yamada Y, Inoue M. Torsades de pointes associated with Takotsubo cardiomyopathy in an anorexia nervosa patients during emergence from general anesthesia. Middle East J Anaesthesiol. 2016;23(5):557-61.

8. Tagami T, Mertens A, Rothschild D, Chowdhury P. A case of reverse takotsubo cardiomyopathy caused by an eating disorder. J Cardiol Cases. 2016;15(3):77-9.

9. Ikegami Y, Momiyama Y. Demonstration of sympathetic nerve innervation in a patient with takotsubo cardiomyopathy using single-photon emission CT. BMJ Case Rep. 2017;2017:bcr2017219438.

10. Elikowski W, Małek-Elikowska M, Marcinkowski P, Komendzińska-Ognik D, Rzymski S. Takotsubo cardiomyopathy triggered by profound hypoglycemia in a 39-year-old female with anorexia nervosa: strain monitoring of left ventricle function recovery. Pol Merkur Lekarski. 2018;45(265):41-5.

11. Duval I, Doberentz E, Madea B. Fatal bleeding after transfemoral coronary angiography in anorexia nervosa. Forensic Sci Med Pathol 2021 Feb 4. doi:10.1007/s12024-021-00354-4. Online ahead of print.

12. Akashi YJ, Nef HM, Lyon AR. Epidemiology and pathophysiology of Takotsubo syndrome. Nat Rev Cardiol. 2015;12(7):387-97.

13. Prasad A, Lerman A, Rihal CS. Apical ballooning syndrome (Tako-Tsubo or stress cardiomyopathy): A mimic of acute myocardial infarction. Am Heart J. 2008;155:408-17.

\section{Figures}




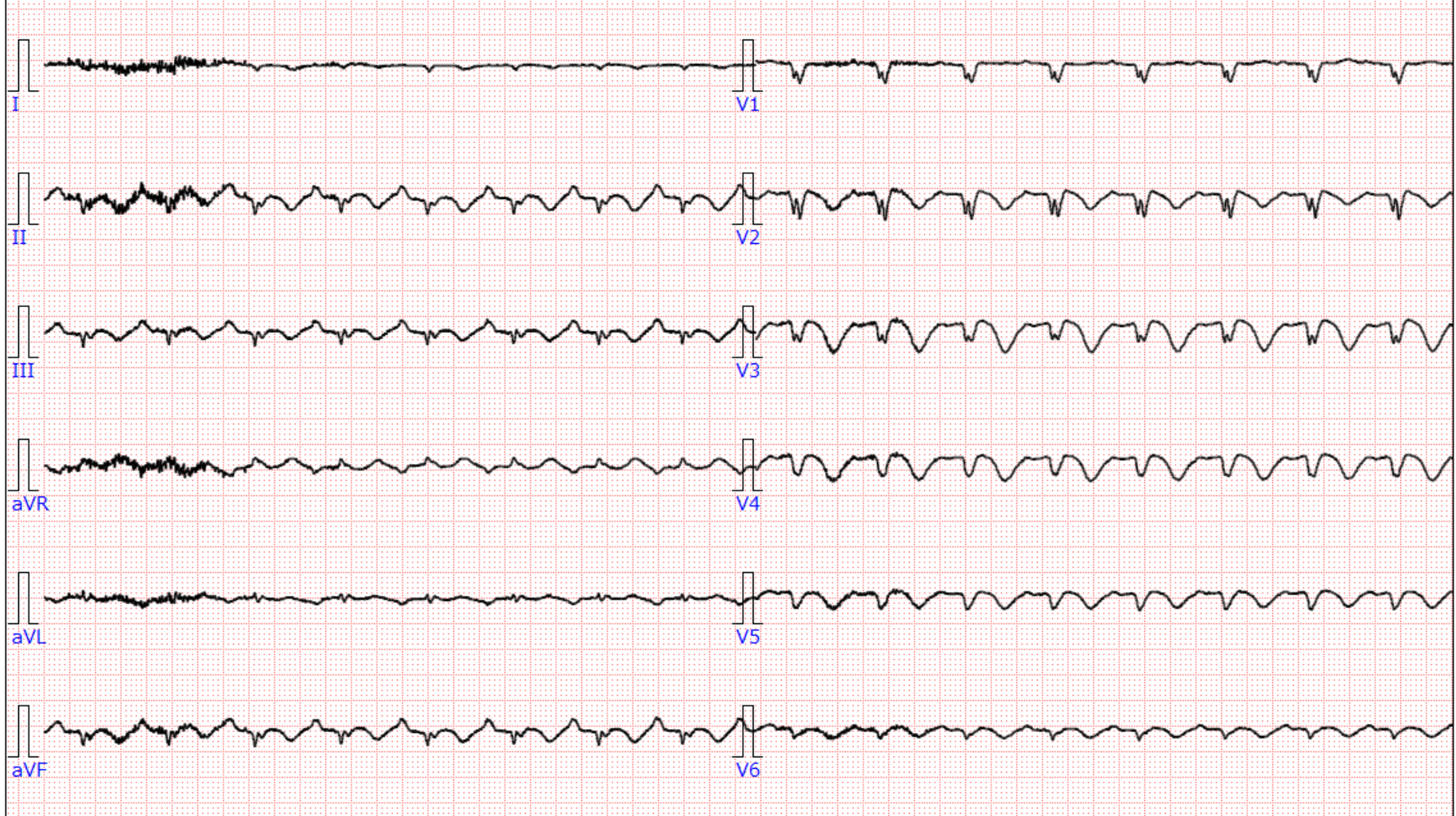

\section{Figure 1}

ECGs on the 3rd (upper) and 12th (lower) days of hospitalization.

(10.00m 25.0mm/s 25Hz)


Figure 2

Heart rate 78/min, ST depression at II/III/aVF/V1-6, P-R: 0.237 seconds, QTc: 0.516 